\title{
Authors' response: Is a reduced duration of post- discharge surgical site infection surveillance really in our best interests?
}

M B Koek (mayke.koek@rivm.nl) ${ }^{1}$, on behalf of the authors of the original article ${ }^{2}$

1. Department of Epidemiology and Surveillance, Centre for Infectious Disease Control, National Institute for Public Health and Environment (RIVM), Bilthoven, the Netherlands

2. http://eurosurveillance.org/ViewArticle. aspx?Articleld $=21042$

Citation style for this article:

Koek MB, on behalf of the authors of the original article. Authors' response: Is a reduced duration of post-discharge surgical site infection surveillance really in our best interests?. Euro Surveill. 2015;20(13):pii=21082. Available online: http://www.eurosurveillance.org/ViewArticle.aspx?Articleld=21082

Article submitted on 24 March 2015 / published on 02 April 2015

\section{To the editor:}

We would like to thank Dr Davies and Dr Patel for their interest in our paper. We agree with them that it is important to advance our knowledge in order to try to eliminate the occurrence of surgical site infections (SSIs) [1]. In order to do so there are several instruments, and surveillance of SSIs is only one of them. Surveillance of SSIs is a standardised way to monitor and report SSIs, allowing comparison within and between hospitals and triggering improvement of internal processes.

For surveillance purposes, we consider it justified to shorten the duration of post-discharge surveillance (PDS), as not only the calculated SSI incidence but also the workload involved in PDS and the speed of feedback to the healthcare professional must be considered. The results of our paper clearly demonstrate that the majority of the SSIs occur within 90 days, and a shorter PDS will substantially facilitate prompt feedback of surveillance results to the healthcare professionals [2].

For clinical purposes however, it is still possible (and sometimes even advisable) to trace all SSIs, regardless of the time when they arise or of their cause. While the 90-day incidence of SSIs might be slightly lower than the one-year incidence, it might also be more accurate since it better represents truly surgery-related SSIs (instead of SSIs due to secondary causes, such as for instance bacteraemia). As such, the use of a 9o-day PDS may improve the accuracy of studies investigating preventive or combative interventions.
Finally, we would like to emphasise that incidence by definition is a measure of frequency during a given time period [3]. Therefore, by reducing the duration of PDS, the incidence itself is not artificially reduced as Davies et al. conclude, but the incidence is measured during a shorter given time period. We would therefore not recommend to directly compare one-year incidences with 90-day incidences without taking into account the shorter duration of PDS.

\section{Conflict of interest}

None declared.

\section{Authors' contributions}

Mayke BG Koek wrote the letter on behalf of the authors of the original article.

References

1. Davies BM, Patel HC. Letter to the editor: Is a reduced duration of post-discharge surgical site infection surveillance really in our best interests? Euro Surveill. 2015;20(13).

2. Koek M, Wille J, Isken M, Voss A, van Benthem B. Postdischarge surveillance (PDS) for surgical site infections: a good method is more important than a long duration. Euro Surveill. 2015;20(8):21042. http://dx.doi.org/10.2807/1560-7917. ES2015.20.8.21042 PMID:25742435

3. Rothman KJ. Measuring Disease occurrence and causal effects. Epidemiology. An introduction. Oxford University Press. New York. 2002:24-56. 